\title{
Modeling and Analysis of Wave Power Generation using Permanent Magnet Linear Synchronous Generator
}

\author{
Joon Sung Park ${ }^{1,3}$, Jun-Hyuk Choi ${ }^{1}$, Gyung-Sun Ham ${ }^{1}$, Jong-Su Choi ${ }^{2}$, Junbo Yun ${ }^{3}$, and Ju Lee ${ }^{3}$ \\ ${ }^{1}$ Intelligent Mechatronics Research Center \\ Korea Electronics Technology Institute (KETI) \\ 203-101 Bucheon T/B 388, Songnae-daero, Wonmi-gu, Bucheon-si, Gyeonggi-do (Korea) \\ Phone/Fax number:+82-31-621-2860, e-mail: parkjs@keti.re.kr \\ ${ }^{2}$ Offshore Plant Research Division \\ Korea Research Institute of Ships \& Ocean Engineering (KRISO) \\ 32, Yuseong-daero 1312 beon-gil, Yuseong-gu, Daejeon (Korea) \\ ${ }^{3}$ Department of Electrical Engineering \\ Hanyang University \\ 222, Wangsimni-ro, Seongdong-gu, Seoul (Korea)
}

\begin{abstract}
This paper describes ocean wave power generation by using permanent magnet linear synchronous generator. The preliminary analysis has shown that a linear generator enables substantial simplification of the mechanical system with respect to a dc generator case [1]. The linear motor has been adopted, taking into consideration the features of the incident waves and the behavior of the floating buoy. The floating buoy is placed on the ocean surface and connected to the generator. The wave energy is carried out from the movement of a buoy. An electrical conversion system is needed between the generator and the grid. For an analysis of the power system, the modeling of the linear generator and converter system was proceeded. This paper aims at studying the electrical part of the wave energy converter and study what impact the electrical system will have on the generator.
\end{abstract}

\section{Key words}

Ocean wave energy, Power Conditioning System(PCS), Permanent Magnet Linear Synchronous Generator (PMLSG)

\section{Introduction}

The use of renewable energy is becoming more wide spread. New approaches, for power generation, are being conducted actively. Among various energy resources, offshore energy technology is still progressing slowly compared to other renewable energy technologies. Ocean wave energy of marine energy can be easily seen and utilized widely. The ocean wave power generation system is utilized with offshore wind power generation system because the place for the development of ocean wave generation is usually consistent with the location of offshore wind power system.
In this paper, we applied the permanent magnet linear synchronous generator (PMLSG) for the wave power generation. The wave energy is carried out from the movement of a floating buoy. The buoy is connected to the moving part of the generator. When the buoy moves with the ocean waves, the permanent magnetized translator gets a linear motion in the generator and a voltage is induced in the stator winding. Since the motion of the translator is correlated with the wave motion, the voltage produced by the wave energy converter has an irregular amplitude and frequency and has to be converted before it connected to the grid. For an analysis of the power system, the modeling of the linear generator and converter system was proceeded. This paper aims at studying the electrical part of the wave energy converter and study what impact the electrical system will have on the generator. Models for studying wave power are often made very complex and include often all parts. A model like that would take a long time to simulate and its complexity could increase the possibility for errors. Instead, a simpler model is used in this paper, where the generator is represented by its electrical components which are resistance, inductance, and back-EMF. The model has been constructed in MATLAB-Simulink, which is a common used simulation program for electrical systems.

Two different cases are studied. First, the wave power generation system is single operation. At single operation, we considered that 1 PMLSG and 1 converter are operated. And second, the power generation system is group operation. At group operation, we considered that 24 PMLSG and 24 converters are operated. The analysis of group operation is required because the buoy speed is irregular. 


\section{Modeling and System Configuration}

\section{A. Dynamic Model of Wave Generator}

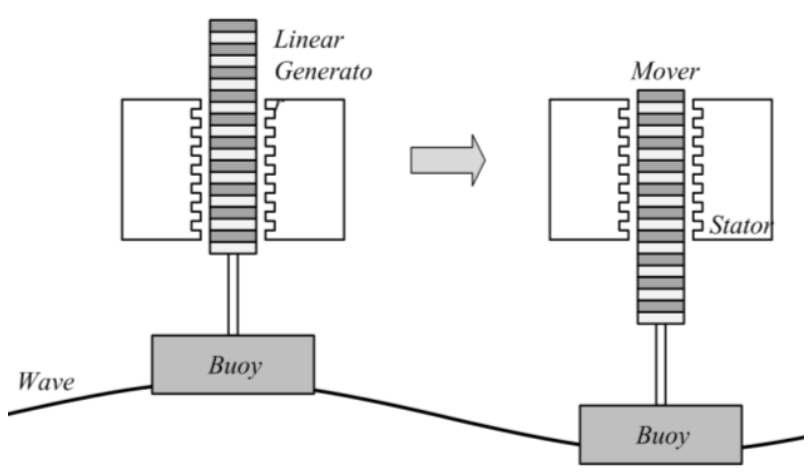

Fig. 1. Wave generator model

Fig. 1 shows the wave generation model. The forces acting on the wave generation system were analyzed in [2] and [3], and detail motion equation of the wave generation system was also derived. Based on the motion equation, a simplified motion equation was given in [1], which is suitable for power system analysis. The simplified motion equation is given by

$$
F_{\text {wave }}=\left(M+m_{a}\right) \frac{d^{2} y(t)}{d t^{2}}+(b+c) \frac{d y(t)}{d t}+K y(t)
$$

where $y(t)$ is the displacement of the translator, $M$ is the mass of the translator, $m_{a}$ is the added mass, $b$ is the radiation damping coefficient, $K$ is the spring constant, $c d y(t) / d t$ is the generator electromagnetic force, and $F_{\text {wave }}$ is the sum of the forces.

\section{B. Modeling of Linear Generator}

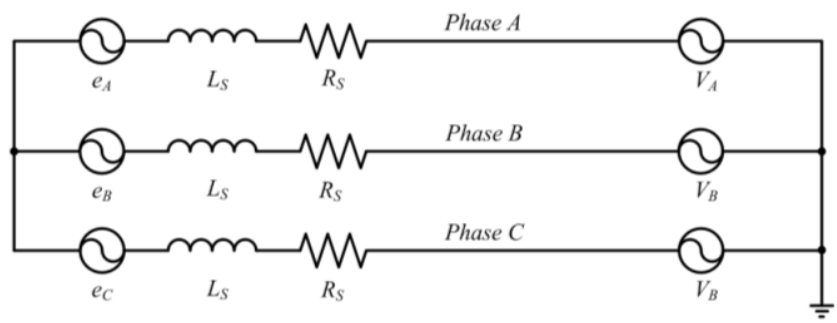

Fig. 2. Equivalent circuit of PMLSG and converter

Fig. 2 shows the equivalent circuit of a linear generator and a converter. The PMLSG is represented by a back EMF, inductances and resistances. The voltage sources represent converter. It is well-known that the dynamic analysis of a permanent magnet synchronous generator is normally established in the dq reference frame. But, the model shown in fig. 2 is represented in abc frame. Therefore the model of the PMLSG in abc reference frame should be transformed into dq reference frame using $\mathrm{dq}$ transformation.
The stator voltage equation of a permanent magnet synchronous generator in the synchronous reference frame is described by [5]

$$
\begin{aligned}
& v_{d}=-R i_{d}-\frac{d \psi_{d}}{d t}+\omega L_{q} i_{q} \\
& v_{q}=-R i_{q}-\frac{d \psi_{q}}{d t}-\omega\left(L_{d} i_{d}-\psi_{P M}\right) \\
& P=\frac{3}{2} \omega \psi_{P M} i_{q}
\end{aligned}
$$

where $v_{d}$ and $v_{q}$ are the $\mathrm{d}$ and $\mathrm{q}$ axis stator voltage, respectively, $i_{d}$ and $i_{q}$ are the $\mathrm{d}$ axis and $\mathrm{q}$ axis stator current, $\omega$ is the angular speed of the stator variables, $\Psi_{P M}$ is the flux from permanent magnet, $P$ is the active power. The voltage equation shown in (2) is appropriate for a rotating permanent machine. because of difference of operation, the speed term should be considered. The voltage equation of the linear generator in the reference frame is derive [6],[7]

$$
\begin{aligned}
& v_{d}=-R i_{d}-\frac{d \psi_{d}}{d t}+v_{t} \frac{\pi}{\tau_{p}} L_{q} i_{q} \\
& v_{q}=-R i_{q}-\frac{d \psi_{q}}{d t}-v_{t} \frac{\pi}{\tau_{p}}\left(L_{d} i_{d}-\psi_{P M}\right) \\
& F=\frac{3}{2} \frac{\pi}{\tau_{p}}\left[i_{d} i_{q}\left(L_{d}-L_{q}\right)-\psi_{P M} i_{q}\right]
\end{aligned}
$$

where $\mathrm{F}$ is the force from the generator, $v_{t}$ is linear speed, and $\tau_{p}$ is the pole pitch.

The linear generator is a surface permanent magnet generator. In case of a surface magnet type, the $d$ axis inductance is the same as the $\mathrm{q}$ axis inductance. Therefore, the reluctance torque is not used in this type of generator. The reluctance torque term is canceled. The generating force in equation (3) can be written as

$$
F=-\frac{3}{2} \frac{\pi}{\tau_{p}} \psi_{P M} i_{q} .
$$

In equation (3), the generating force is related to just $q$ axis current. Since the generating force is proportional to the $q$ axis current, the command value of the $d$ and $q$ axis current can be derived as

$$
\begin{aligned}
& i_{d}^{*}=0 \\
& i_{q}^{*}=-\frac{F}{\frac{3}{2} \frac{\pi}{\tau_{p}} \psi_{P M}} .
\end{aligned}
$$

\section{Converter Control}

Fig. 3 shows the control block diagram for the converter controller. The controller aims to extract the maximum power from the wave force. Because of wave force, a floating buoy moves and the translator of generator 
reciprocates. The position and speed of translator is calculated from measured position sensor values. And then, the generating force command is estimated from the calculated position values. The current command is determined by force command and the current controller generates the voltage reference. The PWM duties are determined normally by the space vector PWM (SVM) method from the voltage references $\mathrm{v}{ }_{\mathrm{d}}$ and $\mathrm{v}{ }_{\mathrm{q}}$ in the $\mathrm{dq}$ reference frame. The gate driver controls switches of IGBTs by gating signals from PWM duties.

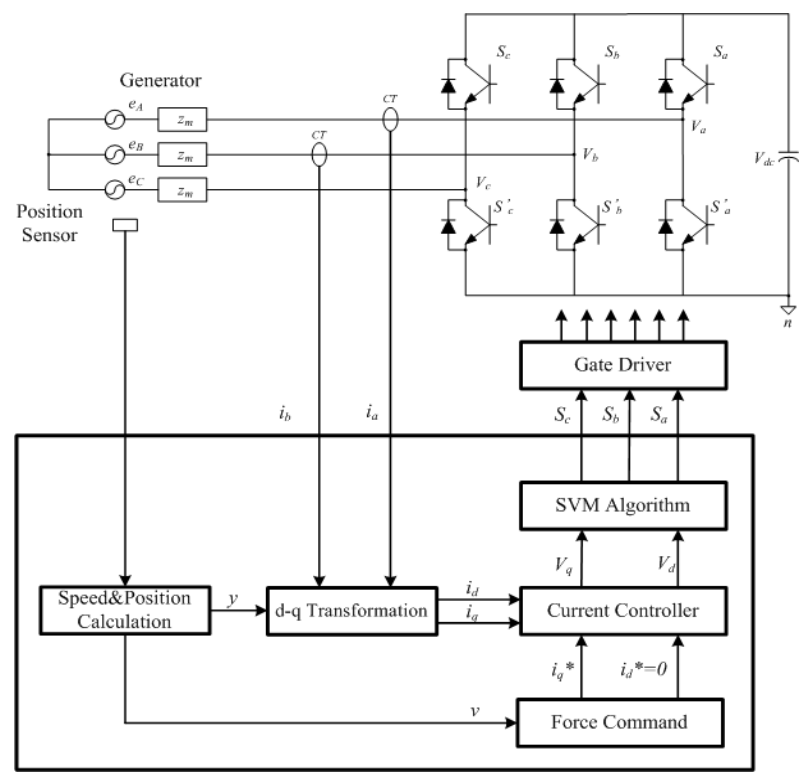

Fig. 3. Converter control block diagram

\section{Simulation Results}

Fig. 4 shows the configuration for a single operation for the PMLSG. The waveform of buoy speed is not uniform because of irregular ocean wave. And a ripple frequency of output power is two times compared to the ocean wave, because the power is generated at non-zero speed region. The simulation was conducted to estimate the output power of the converter and verify the output characteristics.

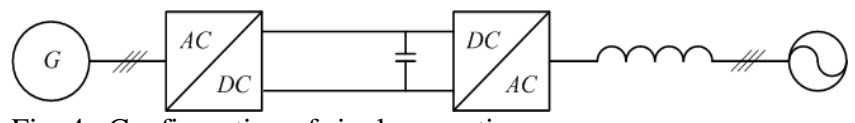

Fig. 4. Configuration of single operation

Table I shows parameters for simulation of the PMLSG. The simulation was performed by irregular ocean wave. Fig.5 shows the irregular buoy speed by irregular wave velocity. Irregular buoy speed varies from $-3.73 \mathrm{~m} / \mathrm{s}$ to 3.52 $\mathrm{m} / \mathrm{s}$.

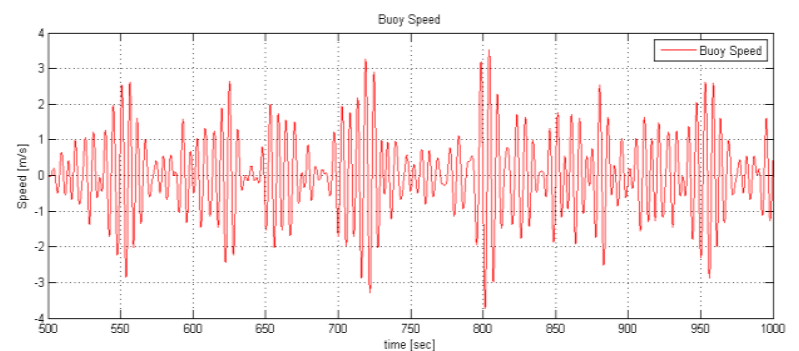

Fig. 5. Irregular buoy speed by ocean wave
Table I. - Specification of linear generator

\begin{tabular}{|c|c|c|}
\hline Parameter & Unit & Specification \\
\hline Phase resistance & $\Omega$ & 0.6458 \\
\hline Phase inductance & $\mathrm{mH}$ & 2.8 \\
\hline Back-EMF contant & $\mathrm{V} / \mathrm{m} / \mathrm{s}$ & 178 \\
\hline Pole pitch & $\mathrm{m}$ & 0.1 \\
\hline
\end{tabular}

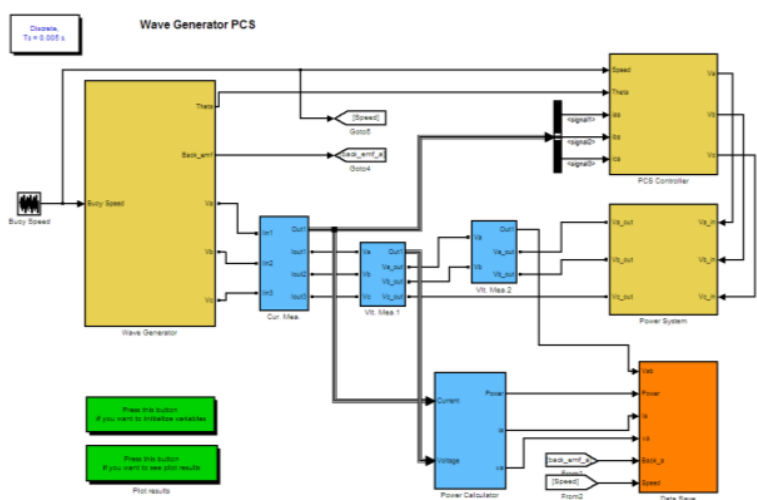

Fig. 6. Simulation block diagram for single operation

We configured the PMLSG and converter, as shown in Fig. 6. Irregular buoy speed is input in the simulation block diagram. Fig. 7 shows the simulation results by irregular buoy speed. The induced voltage and stator current are changed by the buoy speed. The maximum phase voltage was came to $600 \mathrm{~V}$ and the maximum phase current was came to $150 \mathrm{~A}$. The maximum power by irregular buoy speed was $125 \mathrm{~kW}$ and average power was $10 \mathrm{~kW}$. The phase of voltage and current can be controlled by using $\mathrm{d}, \mathrm{q}$ axis current control.
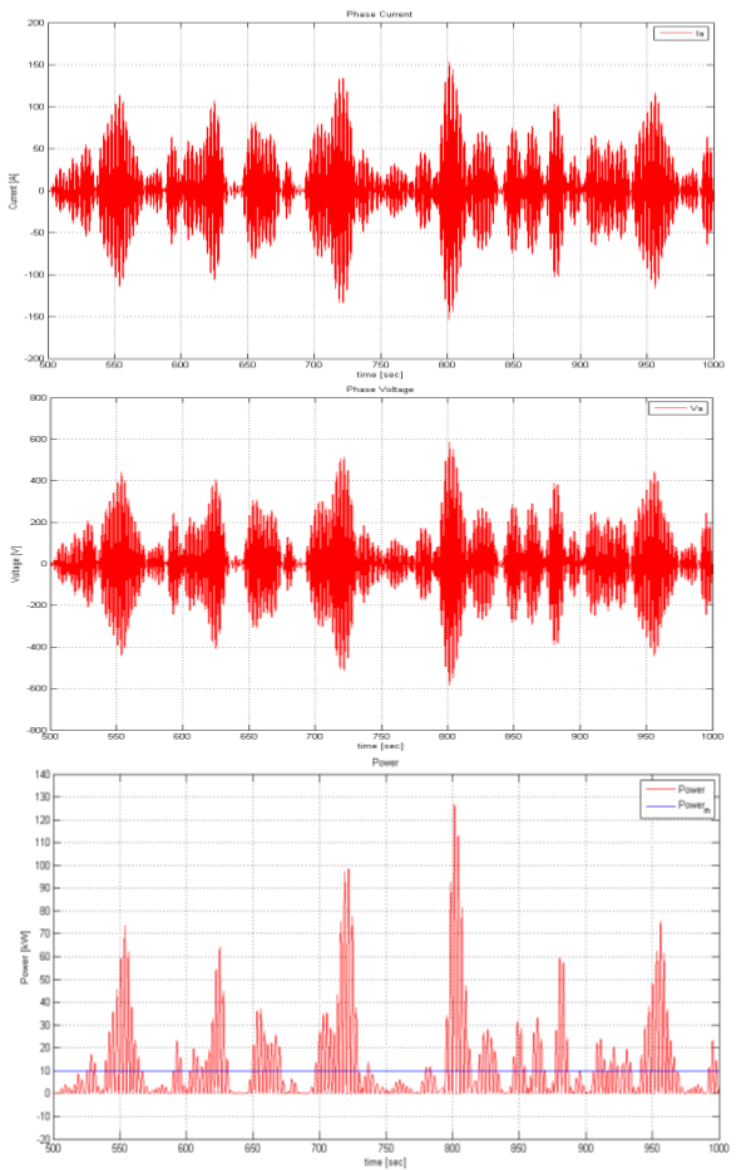

Fig. 7. Simulation results by single operation 


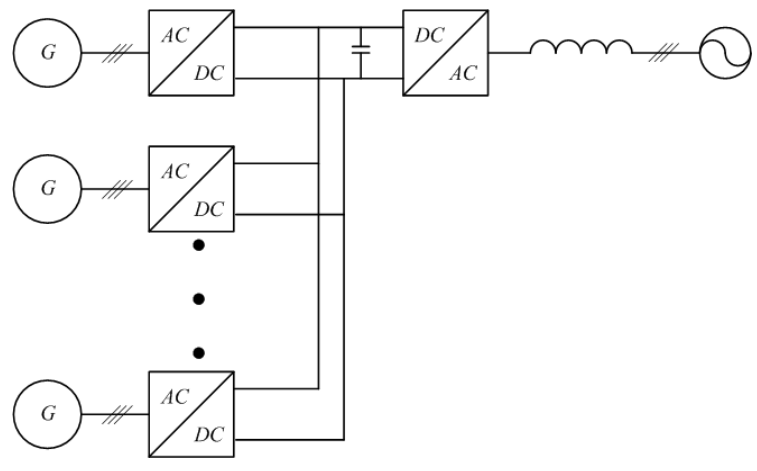

Fig. 8. Configuration of group operation

Fig. 8 shows the configuration for a group operation. we considered 24 generator. In the case of single operation, the power ripple should be appeared because of irregular buoy speed. However, in the case of group operation, the power ripple could be reduced compared to the single operation case. Because each phase of the generator is different. Therefore the output power could not be zero. Fig. 10 shows the simulation results by group operation. The maximum power was $370 \mathrm{~kW}$ and average power was $240 \mathrm{~kW}$.

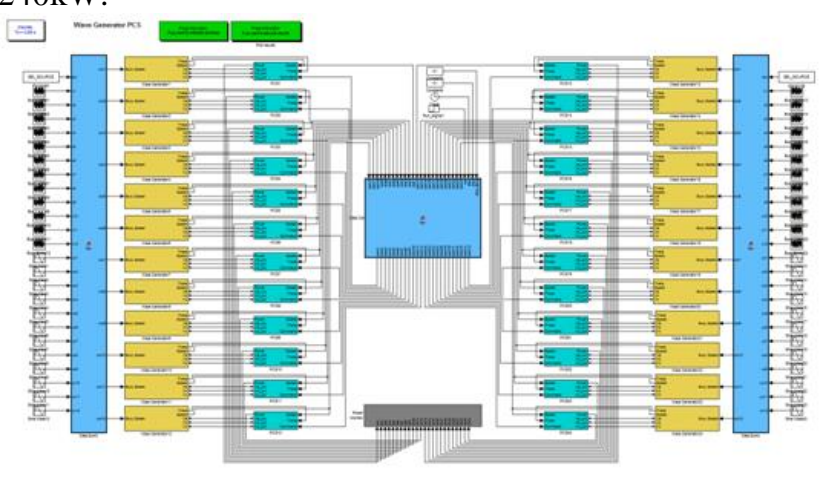

Fig. 9. Simulation block diagram for group operation

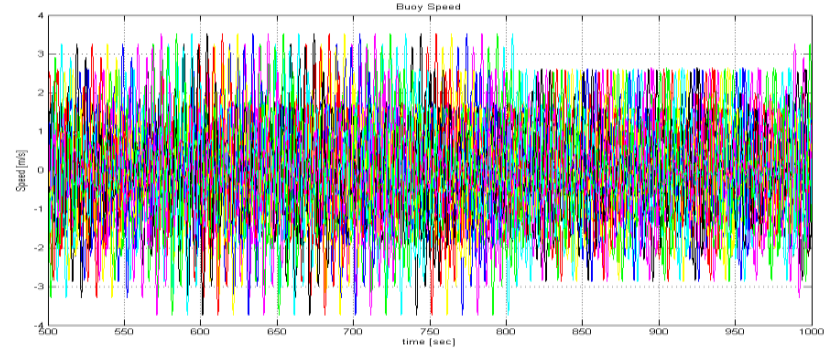

(a) buoy speed

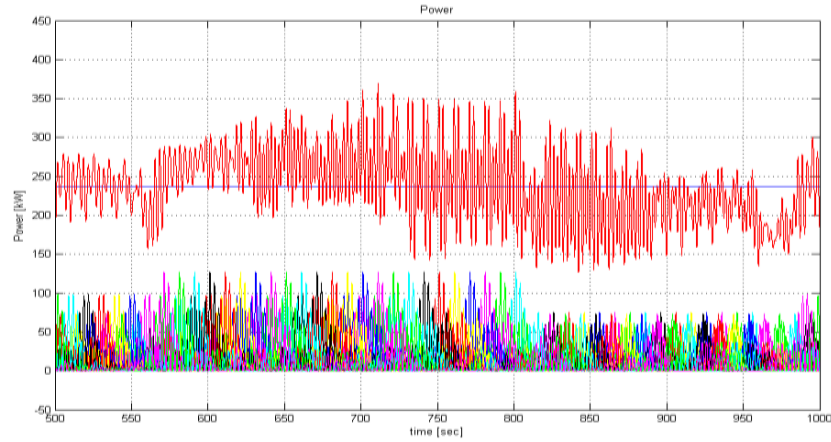

(b) output power

Fig. 10. Simulation results by group operation

\section{Conclusion}

In this paper, we described the power generation from ocean wave by using the linear generator. For the analysis, the wave generation modeling and the simulation were performed. The simulation was performed by two different cases which are both single operation and group operation. The maximum phase voltage was came to $600 \mathrm{~V}$ and the maximum phase current was came to $150 \mathrm{~A}$. The average power by single operation was $10 \mathrm{~kW}$ and the maximum power was $125 \mathrm{~kW}$. The average power by group operation was $240 \mathrm{~kW}$ and the maximum power was $370 \mathrm{~kW}$. The simulation results will be used when the converter is designed. Should clearly indicate advantages, limitations and possible applications.

\section{Acknowledgement}

The present work is a result of the project "Development of the design technologies for a $10 \mathrm{MW}$ class wave and offshore wind hybrid power generation system and establishment of the sea test infra structure" granted by the Ministry of Oceans and Fisheries. All support is gratefully acknowledged.

\section{References}

[1] F. Wu, X.-P. Zhang, P. Ju, and M. Sterling, "Modeling and control of AWS based wave energy conversion system integrated into power grid," IEEE Trans. Power Syst., vol. 23, no. 3, pp. 1196-1204, Aug. 2008.

[2] I. A. Ivanova, O. Ågren, H. Bernhoff, and M. Leijon "Simulation of wave energy converter with octagonal linear generator," IEEE J. Ocean. Eng., vol. 30, no. 3, pp. 619-629, Jul. 2005.

[3] N. Kimoulakis, A. Kladas, and J. Tegopoulos, "Power Generation Optimization From Sea Waves by Using a Permanent Magnet Linear Generator Drive," Magnetics, IEEE Trans., vol. 44, pp. 1530-1533, 2008.

[4] Wenlong Li, Chau K.T., Jiang J.Z., "Application of Linear Magnetic Gears for Pseudo-Direct-Drive Oceanic Wave Energy Harvesting," Magnetics, IEEE Trans. on, Vol. 47, Iss. 10, pp. 2624-2627, 2011.

[5] H. Polinnder, M. E. C. Damen, and F. Gardner, "Linear PM generator system for wave energy conversion in AWS," IEEE Trans. Energy Convers., vol. 19, no. 3, pp. 583-589, Sep. 2004.

[6] Delli Colli, V. ; Dept. of Autom., Univ. of Cassino ; Cancelliere, P. ; Marignetti, F. ; Di Stefano, R., " A Tubular-Generator Drive For Wave Energy Conversion," IEEE Trans. Ind. Elec., vol. 53, pp.1152-1159. 2006.

[7] Jing Zeng ; Barre, P.-J. ; Degobert, ," Modeling and thrust control of PMLSM Using principle of local energ," ICEMS 2003, Six International Conf. vol. 1, pp. 26-30, 2003.

[8] M. Chinchilla, S. Arnaltes, and J. C. Burgos, "Control of permanent magnet generator applied to variable-speed wind- energy systems connected to the grid," IEEE Trans. Energy Convers., vol. 21, no. 1, pp. 130-135, Mar. 2006. 